\title{
Police.uk and Data.police.uk: Developing Open Crime and Justice Data for the UK
}

\author{
Amanda Smith, Tom Heath \\ Open Data Institute (ODI), 65 Clifton Street, London, EC2A 4JE, United Kingdom, amanda.smith@theodi.org \\ tom.heath@theodi.org
}

\begin{abstract}
In this paper we describe the evolution and development of the police.uk and data.police.uk sites, which publish open data about crime and justice in the UK, and make it accessible and comprehensible to the public. Police.uk has received over 64 million visits (754 million hits) since launching in January 2011. Open crime and justice data represents a key sector in the UK open data landscape, and citizens are keen to engage with the criminal justice system to become more informed about local levels of crime and other policing information. This paper sets out the policing context in the UK, discusses the journey in providing such open data, the processes involved and challenges encountered, and explores possible future developments.
\end{abstract}

Keywords: Open Government Data (OGD), United Kingdom, Home Office, crime, police, national policing, Ministry of Justice, justice data, mapping, data hub, transparency, accountability.

Acknowledgement: This paper is an extended version of the "Open crime and justice data in the UK: a case study of Police.uk and Data.police.uk". The original paper was first presented at the Samos Summit (2014) as part of the Share-PSI thematic network. ${ }^{2}$ In addition, this paper is partially supported by the OpenDataMonitor (FP7) project as part of our work on open data stakeholder requirements.

Crime, justice, and policing are emotive subjects that impact a wide range of stakeholders and often elicit calls for greater transparency. They are also resource intensive, placing significant demands on government and the public sector. These factors make crime, justice, and policing activities ideal candidates for an open data approach, to improve service delivery and increase public engagement.

In this paper we describe the evolution and development of the police.uk ${ }^{3}$ and data.police.uk ${ }^{4}$ sites, which publish open data about crime and justice for England, Wales and Northern Ireland, and make it accessible and comprehensible to the public. We expect this case study to provide a valuable reference point for other practitioners.

\section{Policing in the United Kingdom (UK)}

Within the UK, 43 regional police forces provide policing services across England and Wales, with separate devolved arrangements in place for Northern Ireland ${ }^{5}$ (PSNI) and Scotland ${ }^{6}$ (Police

\footnotetext{
${ }^{1}$ http://samos-summit.blogspot.co.uk/

${ }^{2}$ http://www.w3.org/2013/share-psi/

${ }^{3}$ http://www.police.uk

${ }^{4}$ http://www.data.police.uk

${ }^{5}$ http://www.psni.police.uk

${ }^{6}$ http://www.scotland.police.uk
} 
Scotland). These regional forces are complemented by various domain specialist forces covering, for example, the rail network (British Transport Police ${ }^{7}$ ), defence (Ministry of Defence Police ${ }^{8}$ ) and nuclear sites (Civil Nuclear Constabulary ${ }^{9}$ ). Each police force is led by a Chief Constable, who is accountable by law to the Home Secretary. The Association for Chief Police Officers (ACPO) report ${ }^{10}$ of 2012 provides further detail of the UK's policing structure.

At a local level, neighbourhoods (also referred to as wards or boroughs throughout different regions of the UK) have their own dedicated policing teams working in a defined locality, known as Neighbourhood Policing Teams (NPTs) or Safer Neighbourhood Teams (SNTs). These local policing teams are responsible for engaging with the public to identify their needs, tackle issues of concern in a neighbourhood, and work collaboratively with the public and partners to resolve such issues. They are often seen as the visible 'face' of policing.

\section{Policing Data in the United Kingdom}

Throughout 2008-9, individual police forces started to make crime information and maps available to the public, aimed at raising awareness of and access to NPTs / SNTs, and informing citizens about local levels of crime. Across England and Wales, the provision of such crime information and data was disjointed and could be described as a 'mixed picture', with datasets available in various formats, including (but not limited to) CSV files, PDF documents, Microsoft Excel sheets and Word documents, and physical paper leaflets, newsletters and other printed material. With 43 different approaches being undertaken, and numerous costly IT contracts being set up, there was a need for collaboration in creating a national approach to providing and mapping such data. Although sensitive contractual data was never released, a freedom of information request to the Metropolitan Police Service revealed costs of $£ 208,000$ for their individual force crime map. As a result, the National Policing Improvement Agency (NPIA) ${ }^{11}$ were commissioned to develop a standardised crime map, which would provide the data in a more consistent approach on a timely basis, and allow for comparisons across forces. This led to the launch of the national early 'crimemapper' website ${ }^{12}$ in 2009.

\section{CrimeMapper}

Crimemapper provided the public with details of their neighbourhood policing teams and local stations and events, and for the first time provided data on crime statistics for each police force in England and Wales, updated on a monthly basis. This data was made available at force and 'neighbourhood' level to facilitate closer engagement between the public and their NPT/SNT (see figure 1 and figure 2 below). The ultimate aim was to provide insight to citizens, allowing them to gain a better understanding of local problems, and the police action being taken to address these. The then policing minister, Vernon Coaker, announced that: "By rolling out up-to-date crime maps communities are able to take an informed view about crime in their local area. Providing this information to the public helps to make the police even more accountable."13

\footnotetext{
7 http://www.btp.police.uk/

${ }^{8}$ http://www.mod.police.uk/

9 http://www.cnc.jobs/

${ }^{10}$ http://www.acpo.police.uk/documents/reports/2012/201210PolicingintheUKFinal.pdf

${ }^{11}$ http://www.npia.police.uk/

${ }^{12} \mathrm{http}: / /$ maps.police.uk [to note: website no longer live]

13 http://www.crimemaps.org.uk
} 


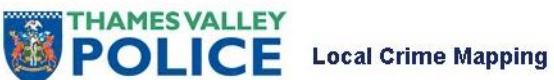

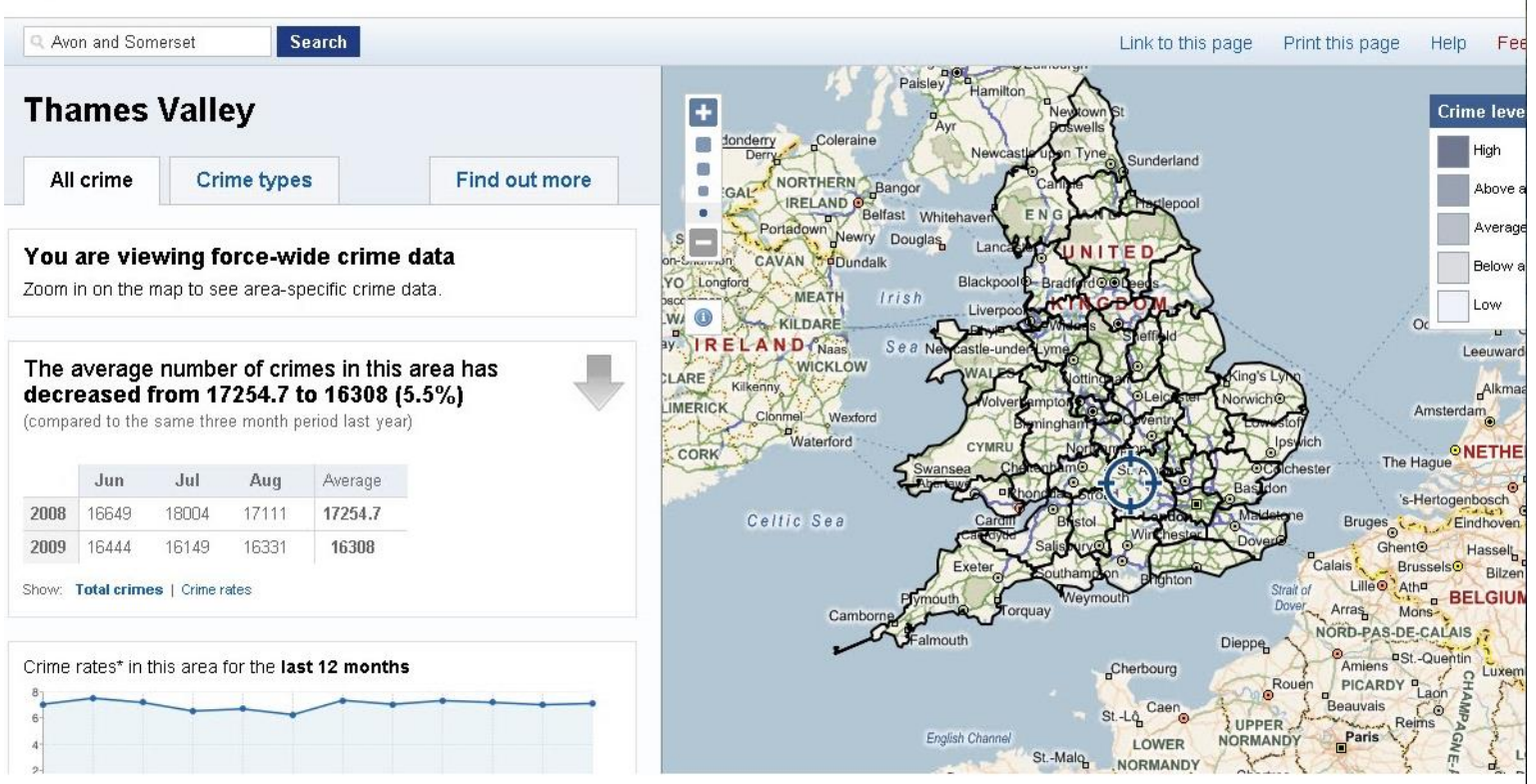

Figure 1: Screenshot of the early crime mapping website, maps.police.uk (at force level for Thames Valley Police $)^{14}$

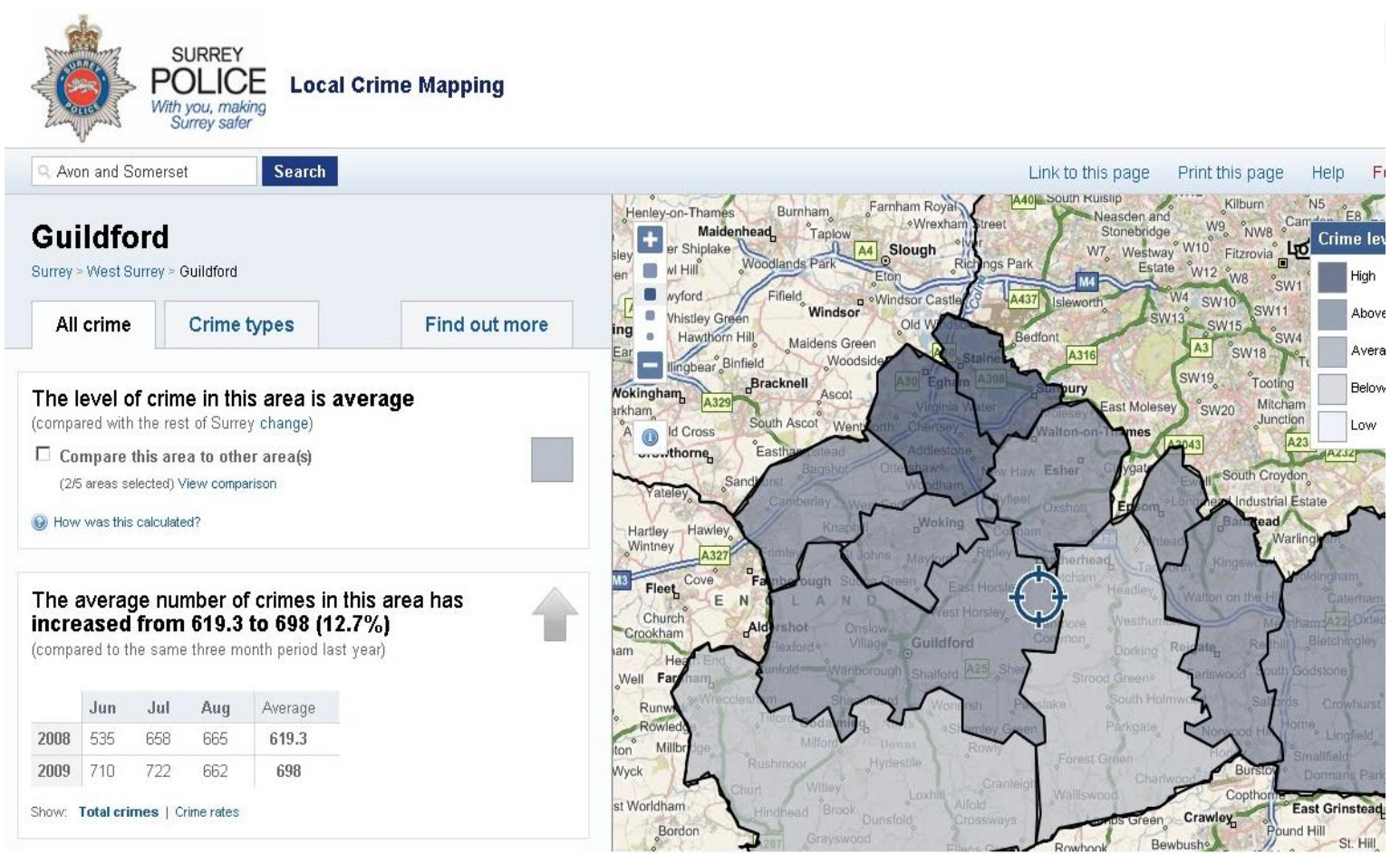

Figure 2: Screenshot of the early crime mapping website, maps.police.uk (at neighbourhood level for Guildford, Surrey Police) ${ }^{15}$

\footnotetext{
14 Image credit: http://2.bp.blogspot.com/ Fbk8IIxNQXM/Stz5Vflad0I/AAAAAAAADto/fyBY-1KTjOY/s1600-
} h/crime maps England Wales.bmp 


\section{The Case for Further Investment}

To understand the impact of providing the public with crime maps and policing information, the NPIA undertook a randomised control trial (RCT) ${ }^{16}$ throughout 2010 (Quinton, 2011). This RCT found that "the public's reaction to information about crime and policing was positive; a large majority thought it was informative and trustworthy." (pp.1)

The study was also able to "challenge the myth that sharing information with the public would increase the 'fear of crime.' In fact, information was found to improve people's perceptions of their neighbourhood and of the local police." (pp.1) Overall, the study concluded that where there is an "investment of police resources in making information available to the public [it] is worthwhile, particularly when integrated with a broader neighbourhood policing approach." (Quinton, 2011)

\section{Change in Government and the Open Data 'Agenda'}

A change of government in 2010 led to a number of significant open data initiatives across government departments and public sector bodies (see Heimstädt et al., 2014, for an overview). Within the crime and policing sector, open data and greater transparency of public sector information sought to achieve:

1) strengthened accountability, and greater engagement by local communities;

2) support for public service improvement, by reducing bureaucracy and by improving trust and confidence levels in the Criminal Justice System (CJS);

3) support for SMEs and other third parties to reuse open data, and develop products and services based on this data.

Government officials were keen to build on the success of the first iteration of crime and policing data, and were keen to replicate the crimespotting.org17 mapping service launched by the San Francisco police department, but nationally across England and Wales (as there are separate devolved arrangements in place for other UK police forces, as set out in section 1 of this paper).

With the evidence base provided by the NPIA RCT, the ambition was set to build upon the success of maps.police.uk to launch police.uk and provide more granular, 'street-level' crime mapping and data. This vision would allow the public to access data on which offences have been reported in their local streets, rather than at an aggregated neighbourhood level. Furthermore, with one central agency co-ordinating the publishing of this data, issues such as data protection, anonymisation processes, and formats and files for download could be tackled once at a national level, rather than by each individual police force. In addition, one single website would provide a seamless, regularly updated, service to the public.

\section{The Development of Police.uk}

In January 2011, police.uk was launched to unexpected levels of public demand, with 300 million hits reported on launch date, resulting in significant periods of down time. The new crime mapping website provided a tailored, personal way of accessing data, with visitors required to input a postcode, street name or town to receive details of the number of crimes in their area.

The website also made available details for local NPTs, crime prevention advice, local events and other ways to get involved. Furthermore, police.uk was designed so that the website itself was

\footnotetext{
15 Image credit: http://3.bp.blogspot.com/ Fbk8llxNQXM/Stz4vum24hl/AAAAAAAADtg/KKsUF5pin5c/s1600h/crime maps England GUILFORD.bmp

${ }^{16}$ http://www.college.police.uk/en/docs/Full Report - Crime and Policing Information.pdf

17 http://sanfrancisco.crimespotting.org/
} 
built on top of an API (application programming interface), with all data on the website being available under the Open Government License v2.0 ${ }^{18}$

\section{Data Management and Publication Workflow}

Every month, each of the 43 police forces ${ }^{19}$ generates a file in a set format that details the crime figures for their force, which also includes anti-social behaviour ${ }^{20}$. These are uploaded to a private server managed by the Home Office and Rock Kitchen Harris (RKH), ${ }^{21}$ the company successfully awarded the contract to deliver police.uk. From here, the file undergoes an internal validation process before being anonymised and published on the website. For the sharing and processing of this personal data, a data processing agreement (DPA) is in place between police forces, Home Office and RKH. The DPA sets out which details are contained in the raw data, and provides important clarification as to the roles and responsibility for all partners involved in the sharing of such sensitive and personal data. The following table explains this anonymisation process.

Table 1: Anonymisation process for police.uk data ${ }^{22}$

\begin{tabular}{|c|c|c|c|c|c|}
\hline Field & $\begin{array}{l}\text { Raw } \\
\text { Example }\end{array}$ & Anonymisation Method & $\begin{array}{l}\text { Anonymised } \\
\text { Example }\end{array}$ & $\begin{array}{l}\text { Published } \\
\text { in CSVs }\end{array}$ & $\begin{array}{l}\text { Published in } \\
\text { API }\end{array}$ \\
\hline $\begin{array}{l}\text { Offence } \\
\text { Reference }\end{array}$ & C2/0123/13 & $\begin{array}{l}\text { Replaced with a } \\
\text { unique one-way hash } \\
\text { of the record }\end{array}$ & $\begin{array}{l}\text { 7512cb691a6f9c6c } \\
\text { 47a2cdfdcd0a1f87 } \\
\text { 35a0870d3a2bde21 } \\
\text { d8311bd74f17eeeb }\end{array}$ & Crime ID & persistent_id \\
\hline Date & $2013-07-23$ & $\begin{array}{l}\text { Truncated to show the } \\
\text { year and month only }\end{array}$ & 2013-07 & Month & date \\
\hline $\begin{array}{l}\text { Home } \\
\text { Office } \\
\text { Offence } \\
\text { Code }\end{array}$ & $104 / 25$ & $\begin{array}{l}\text { Assigned into one of } \\
15 \text { categories. A } \\
\text { complete mapping } \\
\text { between Home Office } \\
\text { Offence Codes and } \\
\text { Categories can be } \\
\text { downloaded }\end{array}$ & $\begin{array}{l}\text { Violence and } \\
\text { Sexual Offences }\end{array}$ & $\begin{array}{l}\text { Crime } \\
\text { Type }\end{array}$ & category \\
\hline Easting & 519500 & $\begin{array}{l}\text { Anonymised in line } \\
\text { with the location } \\
\text { anonymisation } \\
\text { process. Converted to } \\
\text { WGS84 latitude }\end{array}$ & 52.58019 & Latitude & latitude \\
\hline
\end{tabular}

\footnotetext{
${ }^{18}$ http://www.nationalarchives.gov.uk/doc/open\%2Dgovernment\%2Dlicence/version/2/

19 http://www.police.uk/contact/force-websites/

${ }^{20}$ http://content.met.police.uk/Article/What-is-antisocial-behaviour/1400022084553/1400022084553

21 http://www.rkh.co.uk

${ }^{22}$ Source: http://data.police.uk/about/\#anonymisation
} 


\begin{tabular}{|l|l|l|l|l|l|}
\hline Northing & 299500 & $\begin{array}{l}\text { Anonymised in line } \\
\text { with the location } \\
\text { anonymisation } \\
\text { process. Converted to } \\
\text { WGS84 longitude }\end{array}$ & -0.23782 & Longitude & longitude \\
\hline Context & $\begin{array}{l}\text { This was } \\
\text { part of the } \\
\text { recent } \\
\text { public } \\
\text { disorder } \\
\text { events in } \\
\text { the town } \\
\text { centre }\end{array}$ & None & $\begin{array}{l}\text { This was part of the } \\
\text { recent public } \\
\text { disorder events in } \\
\text { the town centre }\end{array}$ & Context & \\
\hline
\end{tabular}

In May 2012, police.uk was further developed to include data on what happened after an individual crime was reported. This additional dataset included either the police action which was undertaken (such as a fine or caution) or, if the crime went to court, the outcome reached from any subsequent court hearing. The monthly data processing was amended, with force files being sent to the Ministry of Justice (MOJ). From here, the data undergoes a matching process to any court results contained in their own records held on the Police National Computer (PNC). This data would then be returned to the Home Office to be integrated with existing data.

The matching process ${ }^{23}$ for linking a crime to a justice outcome involves the use of an algorithm that matches a number of variables contained within the PNC (such as crime reference number, arrest summons number and Home Office offence code). It is important to understand here that due to the various different IT and crime recording systems of the different police forces that not all of these variables are available for each force, and that there is no single identifier on a crime that is attached to a record or file throughout the entire CJS process. In the interests of transparency, each month the various match rates for each forces are available to download ${ }^{24}$. Owing to the extraction (and quality of) the underlying data, this figure varies each month with most recent statistics showing the lowest match-rate as $23 \%$ and highest as $94 \%$. However, this match rate is only representative of the incidents of crime that go to court, rather than the majority which are dealt with by the police.

\section{Data.police.uk and Reuse of Open Crime and Justice Data}

Following recommended best practice and principles ${ }^{25}$ set out by the Open Data Institute $\left(\mathrm{ODI} \mathrm{I}^{26}\right)$, the data.police.uk portal was launched in July 2013. Although the underlying police.uk data was always available to download and reuse, the new portal makes it easier for users to customise and download large amounts of data in CSV format and provides improved documentation on the $\mathrm{API}$, encouraging greater reuse of the datasets.

As data.police.uk does not require an API key, there are limitations in measuring the re-use of open crime and justice data. However, where developers and local communities have made use of the data, and provided these details, the apps and services are published ${ }^{27}$ on the website.

\footnotetext{
${ }^{23}$ https://www.gov.uk/government/uploads/system/uploads/attachment data/file/217421/police-uk-statistics.pdf\%20

$\underline{24}$ http://data.police.uk/data/match rates.zip

25 https://certificates.theodi.org/

$\underline{26}$ http://theodi.org/

27 http://www.police.uk/apps/
} 


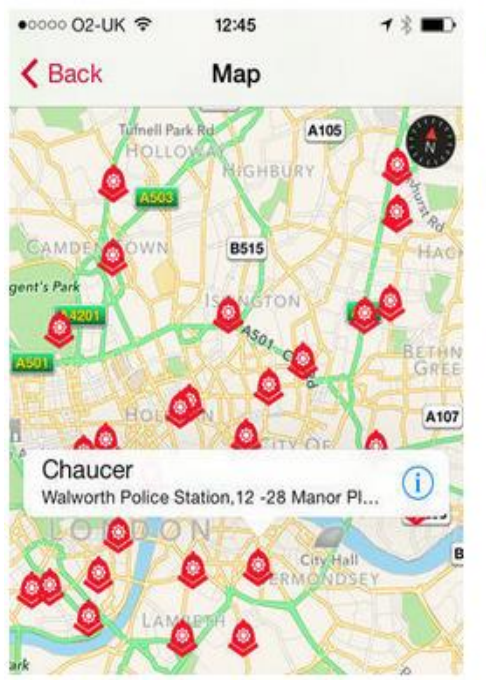

\title{
My Legal Places
}

\begin{abstract}
From police stations to law courts, Citizens Advice Bureau to Community Legal Offices - the application identifies your nearest key service, pinpoints it on a map, and provides you with full contact details, that can be saved and added to your favourites.
\end{abstract}

View this app 圆

Figure 3: A screenshot from the police.uk apps page demonstrating an example of an app created using open crime and justice data. My legal places ${ }^{28}$ provides users with details of their nearest police station, court, citizen advice bureau and community legal offices.

\section{Managing the Challenges: Anonymisation, Privacy and Accuracy of Data}

Once formally tasked with the process of delivering street-level crime mapping, the NPIA set up a steering group which would work collaboratively on understanding and addressing the issues, potential challenges and public benefits. As the raw data collected from individual forces contained information relating to identifiable persons and locations, the overarching aim of this group was to design the appropriate solution which would safeguard victims of crime whilst providing the public with more detailed, granular data. Amongst the tactical advisory members were the Information Commissioners Office (ICO), ${ }^{29}$ Home Office statisticians, and a number of experts from various police forces, including Chief Constables and ACPO leads ${ }^{30}$ - the data controllers and agencies with whom the legal liability for such data rests.

In providing personal data at such a granular level, one of the biggest challenges is ensuring that there is a balance between transparency of data and privacy for victims, ensuring that it isn't possible to identify individual addresses, victims and offenders. To ensure the safeguarding of such personal detail, the design solution for crime mapping could not include the pinpointing of individual crimes. As an alternative, the approach of 'snap points' was incorporated within the design solution.

These snap points were placed in the centre of the road where the crime had occurred (see figure $3 \mathrm{a}$ and $3 \mathrm{~b}$ below) and covered a minimum of 12 postal addresses. Where an incident has occurred on a street with fewer than 12 postal addresses, the snap point was 'moved' to the nearest street with the required minimum number of postal addresses. To make it clear to the public that crimes may not have occurred in that exact location, the wording 'on or near x road' was used throughout the map.

This can, however, be seen to be making compromises on the accuracy of the mapping and data (particularly the location) and affect public confidence and trust in the data if they are aware that a crime didn't happen specifically there. To improve the location accuracy, the threshold for

\footnotetext{
${ }^{28}$ https://itunes.apple.com/gb/app/my-legal-places/id806005621?mt=8

29 http://ico.org.uk/

${ }^{30}$ http://www.acpo.police.uk/acpobusinessareas/default.aspx
} 
snap points was later reduced to 8 postal addresses and snap points were added to 'points of interest' (car parks, shopping centres, recreational areas) rather than just residential roads.
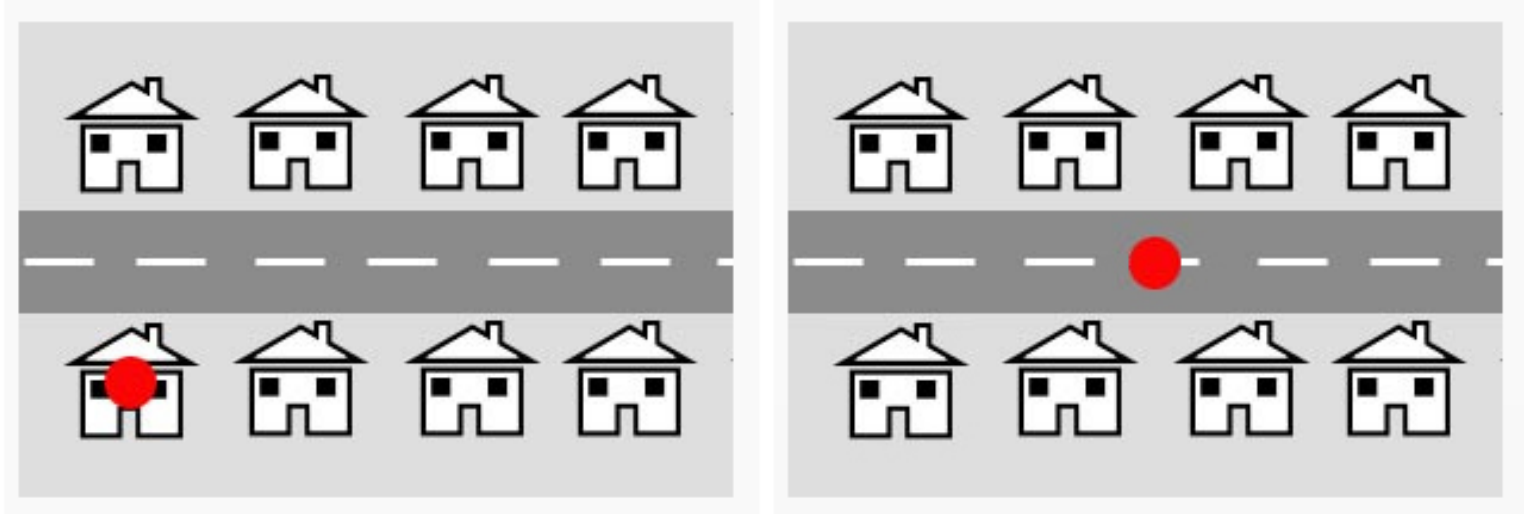

Figure 3(a). Location of crime occurrence

Figure 3(b). Location of 'snap point' used ${ }^{31}$

Ahead of launching police.uk, a detailed Privacy Impact Assessment (PIA) was completed which has been treated as a 'living' document, which continues to be maintained and is available upon request. All correspondence and feedback received is monitored to ensure that there are no issues raised pertaining to privacy.

In addition to the anonymisation process for such data, the accuracy of mapping also poses challenges. As mentioned in detailing the 'snap point' approach, crimes are mapped at approximate locations. However, in some instances there may simply not be a given location for a crime, for example, if the victim may not know or be able to recall where a crime took place. With such no-location crimes, the data cannot be mapped, as shown in the police.uk screen-shot below. Other geolocation issues can affect the accuracy of crime data and understanding its exact location. For example, force gazetteer systems may only be able to give the location of a crime as being on "High Street" but be unable to more accurately describe what section or which residence / point of interest more specifically, which can skew the perceived location of a crime.

\footnotetext{
${ }^{31}$ Image credit: http://www.cheshire.police.uk/about-us/statistics/crimemapping.aspx
} 


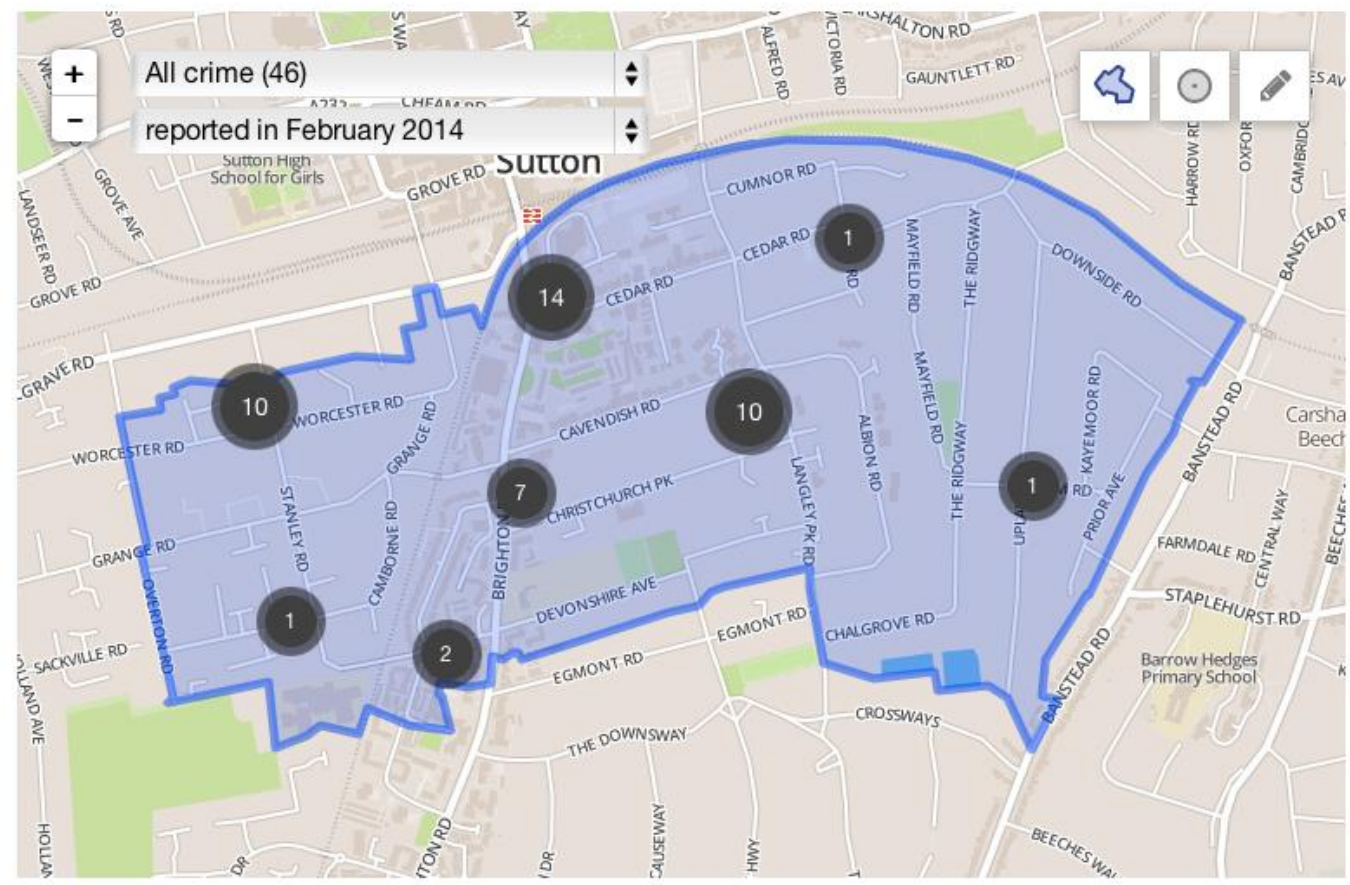

723 incidents of crime occurred in Metropolitan Police Service that could not be mapped to a specific location. Why?

Figure 4: Screen shot of the police.uk 'street-level' crime map clearly explaining the number of crimes that the force were unable to map to a specific location for this particular month.

Finally, in achieving reuse of public sector data, there is a challenge in understanding the 'role' of Government in the marketplace, and how best to support third party developers and other interested individuals and groups wishing to make use of this data. Should Government be providing both the mapping services and the data, or just the underlying data? Is there a need for the provided mapping system to make the data easy to interpret for those who don't have the knowledge or skills to use APIs? Alternatively, if the mapping service that police.uk provides is removed, would it open up the market space for a developer to replicate / create their own crime maps? In February 2013, the ODI hosted an 'open data comes to market' roundtable where such issues were discussed. To document the discussion, a report ${ }^{32}$ was drafted by the Crime and Justice transparency sector panel for Crime and Criminal Justice (O'Hara, 2013).

\section{Future Developments for Police.uk}

Police.uk continues to prove popular with the public, with 64 million visits to the site and 754 million hits since January $2011 .{ }^{33}$ It is likely that the Government will continue to focus on improving the quality of the underlying data, whilst ensuring that there is no additional burden or bureaucracy on those involved in the process, against the challenge of working with IT systems that prove problematic for extracting such data.

With the merging of all eight regional forces into a single Police Scotland, it would be worth recommending that this body works closely with Home Office and Government to release similar

32 http://eprints.soton.ac.uk/350043/1/Open\%20Data\%20Comes\%20to\%20Market\%20report\%20final.pdf

${ }^{33}$ Figures dated January 2011 - September 2014. Throughout February 2014, the site received 567,966 visits. 
data for Scotland, or understand the challenges and lessons learnt in providing this data for England, Wales (and later included Northern Ireland, who started to provide their crime data on police.uk in December 2012). The upcoming challenges continue to be the provision of accurate, high quality data, mapped in a way that protects victims but also gives the public confidence in the accuracy of the mapped location. Furthermore, increasing the frequency of data release (currently monthly) or splitting crimes into day/night would be more useful to the public, as well as providing real-time data such as the nearest open police station or counter, and easily accessible online crime reporting and submitting digital evidence.

\section{References}

Quinton, P. (2011) The impact of information about crime and policing on public perceptions: The results of a randomized controlled trial. National Policing Improvement Agency. Retrieved October 14, 2014, from: http://www.college.police.uk/en/docs/Full Report - Crime and Policing Information.pdf

Heimstädt, M., Saunderson, F., \& Heath, T. (2014) Conceptualizing Open Data Ecosystems: A Timeline Analysis of Open Data Development in the UK. In Proceedings of the International Conference for E-Democracy and Open Government (CeDEM2014), Krems, Austria. Retrieved October 15, 2014, from: http://project.opendatamonitor.eu/images/downloads/conceptualizing-open-data-ecosystems-a-timeline-analysis-ofopen-data-developments-in-the-uk.pdf

O'Hara K. (2013) Open Data Comes to Market: Report of a discussion seminar at the Open Data Institute. Retrieved October 14, 2014, from: http://eprints.soton.ac.uk/350043/1/Open\%20Data\%20Comes\%20to\%20Market\%20report\%20final.pdf

\section{About the Authors}

Amanda Smith

Amanda is the Community Engagement Manager at the Open Data Institute. She is primarily responsible for managing our two EU funded FP7 research projects; DaPaaS (Data-and-Platform-as-a-Service) and ODM (OpenDataMonitor) and is the ODI's lead for the Share-PSI project, thematic network of practitioners across Europe who exchange experience and ideas around implementing open data policies in the public sector. Before joining the ODI, Amanda worked in policing and government, and she holds a BA Hons in Criminology. She discovered her passion for open data when working with police forces throughout the country to release open crime and justice data, developing the national crime mapping website, Police.uk and its data site Data.police.uk. As a Staff Officer to a number of senior officers she has had responsibility for wide range of national policing portfolios. Amanda has been honoured with Chief Constable commendations 3 times in her career, including the successful delivery throughout England and Wales of the Neighbourhood Policing Programme.

\section{Dr. Tom Heath}

Dr Tom Heath is Head of Research at the Open Data Institute, where he has responsibility for developing and managing the ODI's research programme. Reflecting the breadth of interest in open data this programme is multidisciplinary in nature, with an emphasis in the computing and social sciences, and includes both publicly and commercially funded projects. Tom oversees collaborative research proposals and projects involving the ODI, in addition to the institute's internship and visiting researcher programmes. Tom joined the ODI from Talis Group, where he led internal research and data science programmes drawing heavily on Open and Linked Data. He is the co-author of several highly cited publications on the topic of Linked Data, and the recipient of a number of awards including Semantic Web Challenge winner 2007 and STI International PhD of the Year 2008/9. Tom has a BSc in Psychology from the University of Liverpool and a PhD in Computer Science from The Open University. 